Public access - Manuscript accepted

Published in final edited form as: Plasma Process and Polymers 12 (4): 314-327, 2015

(doi.org/10.1002/ppap.201400147)

\title{
PLASMA-ETCHING FOR CONTROLLED MODIFICATION OF STRUCTURAL AND MECHANICAL PROPERTIES OF ELECTROSPUN PET SCAFFOLDS
}

\author{
Houman Savoji, Sophie Lerouge, Abdellah Ajji, Michael R. Wertheimer*
}

Houman Savoji, Prof. Abdellah Ajji, Prof. Michael R. Wertheimer

Institute of Biomedical Engineering, École Polytechnique de Montréal, Montreal, QC, H3C 3A7, Canada

Houman Savoji, Prof. Sophie Lerouge

Laboratory of Endovascular Biomaterials (LBeV), Research Centre, Centre Hospitalier de l'Université de Montréal (CRCHUM), Montreal, QC, Canada

Prof. Sophie Lerouge

Department of Mechanical Engineering, École de technologie supérieure, Montreal, QC, H3C $1 \mathrm{~K} 3$, Canada

Prof. Abdellah Ajji

Department of Chemical Engineering, École Polytechnique de Montréal,

Houman Savoji, Prof. Michael R. Wertheimer

Department of Engineering Physics, École Polytechnique de Montréal, Montreal, QC, Canada

*E-mail: $\underline{\text { michel.wertheimer@polymtl.ca }}$ 


\begin{abstract}
Aligned electrospun poly(ethylene terephthalate) (ePET) nanofiber mats that mimic the media layer of arteries have been fabricated. In order to bring their mechanical and surface properties in line with those of natural blood vessels, we have used three different plasma etching techniques: (i) atmospheric pressure ("HP") corona discharge in air; low-pressure (ii) radio-frequency discharge ("LP") and (iii) discharge in a microwave plasma asher, the latter two in pure oxygen $\left(\mathrm{O}_{2}\right)$ gas, or $\mathrm{O}_{2}$ mixture with $\mathrm{Ar}$ or $\mathrm{CF}_{4}$. Substantial reduction in Young's modulus has been attained after as little as $5 \mathrm{~min}$. treatment in (iii), without visible damage to the fibers. Changes in surface composition and drastic improvement in surface wettability / wicking have also been observed, which resulted in promoting adhesion and growth of smooth muscle cells (SMCs).
\end{abstract}

Keywords: Nanofibers, Electrospinning, Plasma-etching, Poly(ethylene terephthalate), Mechanical property, Surface chemistry, Vascular graft

\title{
1. Introduction
}

The quest for improved functional small-diameter vascular grafts is great and growing. Currently, the use of autologous grafts from the patient is considered the gold-standard, especially for smalldiameter blood vessels. However, their availability has in practice been a limiting factor due to insufficient or defective donor tissue and danger of patient morbidity associated with harvest surgery [1]. Synthetic grafts such as woven poly(ethylene terephthalate) (PET, Dacron ${ }^{\mathrm{R}}$ ) and expanded poly(tetrafluoroethylene) (ePTFE) have been widely used to replace large-diameter vessels. However, these have shown limited patency when applied to small-diameter $(<6 \mathrm{~mm})$ vessels due to the mechanical and compliance mismatch that lead to intimal hyperplasia [1, 2].

The native artery wall is composed of three distinct layers: the intima, media, and adventitia [3] [4]. Each layer contributes its own biomechanical role, while being subjected to axial, circumferential and torsion forces. The extracellular matrix (ECM), comprising a basement membrane and a complex, chemically and physically cross-linked network of proteins, glycosaminoglycans, collagen and elastin fibers with nanoscale features, plays an important role in controlling cell behavior in living systems $[3,4]$. It is known that the media layer, which contains 
smooth muscle cells (SMCs), collagen fibrils and elastic lamellae, comprises long, parallel and circumferentially aligned fibers. These are essential for arterial contraction and dilation and they facilitate the control of blood pressure and tissue homeostasis [5].

Primary requirements for a functional synthetic vascular graft (VG) are biocompatibility, bioactivity and, most important, favorable mechanical properties [1,6]. The current generation of VGs is limited by (i) inadequate (excessive) mechanical stiffness that leads to compliance mismatch and intimal hyperplasia; and by (ii) lack of spontaneous endothelialization of the lumen surface [7]. Therefore, fine-tuning of the mechanical properties will directly affect the performance of an engineered VG after implantation.

Electrospinning has the potential to produce fiber-based scaffolds similar to the protein fibers of the ECM, with diameters that can range from 50-5000 nm, and consisting of a 3D structure with high porosity and large surface area; this technique uses polymer solutions or -melts under high electric field $[8,9]$. An important challenge in attempting to engineer a synthetic vascular graft is to achieve optimum morphological, mechanical and biological properties in each layer. Regarding the media layer, the versatility of electrospinning allows one to organize and orient fibers so that they can guide the migration and elongation of cells [6].

Aligned fibrous mat-scaffolds from selected natural and/or synthetic polymers are under investigation to mimic the media layer, by directing SMCs in a circumferentially aligned orientation similar to that in natural vessels. In addition, aligned fibers can provide the requisite mechanical strength to resist the high pressure encountered in-vivo [9-14]. Electrospun PET (ePET) is an excellent candidate, because it is non-toxic, has good mechanical properties, biodurability, biocompatibility and low cost; however, most important is the fact that PET vascular grafts have already been FDA-approved and clinically used for several decades. Therefore, a number of research groups, including the present authors, have elected to use PET as their vascular biomaterial [15-19].

We have recently shown that tensile properties, including Young's modulus, of random ePET mats are higher than those of natural arteries, but that they can be better than ePTFE, woven or knitted PET in the present context.[19] Moreover, those characteristics can be modified by wet-chemical [20] or dry (plasma-based) etching, if desired. Wet-chemical treatment (e.g. hydrolysis with concentrated $\mathrm{NaOH}$, among others) has so far been the only method proposed in the literature for 
this purpose [20-23], but it generally entrains problems of toxicity, environmental impact, and associated costs, among others [24]. Furthermore, macroscopic damage can result to fibers in contact with $\mathrm{NaOH}$, when the ester linkage of PET is broken (leading to formation of a sodium carbonate salt and ethane1, 2diol) $[25,26]$.

On the contrary, rapid, clean, highly reproducible and environmentally benign plasma etching may offer an attractive alternative to fine-tune the mechanical and surface-chemical properties of ePET fibers. This can be accomplished by controlling treatment parameters such as gas type and flow, power, pressure and treatment time. Cold plasma treatments, both at low- and atmospheric pressure are widely used to modify the inert surfaces of polymers so as to enhance their wettability, roughness and biocompatibility, for example, and to adapt them for biomaterials applications, generally without changing their bulk properties [27-31]. Keller et al. reported a comprehensive study of plasma-based and wet-chemical removal of manufacturing residuals from PET multifilament fibers, concluding that radio-frequency plasma in $\mathrm{He} / \mathrm{O}_{2}$ is the best option for various reasons [32]. Verdonck et al. used SEM to investigate the influence of $\mathrm{O}_{2}$ plasma etching on the morphological properties and fiber diameter distribution of electrospun polyacrylonitrile (PAN) fibers, including etch mechanisms in the reactive-ion etching (RIE) mode. They concluded that etching was more rapid in the presence of ion bombardment and for smaller-diameter nanofibers [33]. Zandén et al. also used $\mathrm{O}_{2}$ plasma treatments of electrospun polyurethane (PU), for durations up to 7 minutes, to investigate changes in surface morphology, chemistry and wettability. They observed fiber diameter reduction, increased porosity and modified fiber surface texture, accompanied by structural degradation after longer exposure times. The initially hydrophobic membranes were observed to become hydrophilic and water-absorbing, but the authors found that neither pristine nor plasma-modified samples had an effect on the shape of red blood cells (RBC), the function of which remained intact [34]. Finally, a very recent study by Jeon et al. reported $\mathrm{O}_{2}$ plasma-based creation of sub-micrometer sized surface patterns, with the aid of special templates, on mats of electrospun poly(e-caprolactone) (PCL) fibers. The authors showed SEM images corresponding to plasma exposures up to 120 minutes. Stress-strain tests revealed weakening (decrease in Young's modulus, strength and elongation at break), attributed to the fibers' roughened surfaces. Finally, they described enhanced attachment and proliferation of (MG63) osteoblast-like cells, claiming the materials' suitability for tissue engineering applications [35]. 
Clearly, some of the above-cited work has utilized $\mathrm{O}_{2}$ plasma to etch or surface-modify various electrospun fibrous mats for cell-biological purposes. However, none of the authors have specifically mentioned plasma-etching as a potential process to fine-tune the mechanical properties of electrospun fiber mats, certainly not in the context of vascular grafts. Therefore, the objective of the present study has been to investigate the effects of low- and high (atmospheric-) pressure plasma-etching on mechanical, morphological, chemical and biocompatibility properties of partially aligned electrospun PET mat scaffolds, specifically destined for VG applications.

\section{Experimental Part}

\subsection{Fabrication of Aligned Nanofibrous PET Scaffolds}

\subsubsection{Electrospinning}

Partially aligned nanofibrous PET mats (ePET) were prepared by electrospinning of $12.5 \mathrm{wt} / \mathrm{vol} \%$ polymer solution [36]. The polymer solution was prepared by dissolving PET pellets (DuPont selar PT 7086, intrinsic viscosity of 1) in a 1:1 mixture of analytical grade dichloromethane $\left(\mathrm{CH}_{2} \mathrm{Cl}_{2}\right)$ / trifluoro-acetic acid (TFA) (both from Sigma Aldrich), and gently stirring for $24 \mathrm{~h}$. Two (2) $\mathrm{ml}$ of polymer solution was electrospun at a rate of $10 \mathrm{ml} / \mathrm{h}$ with the aid of a syringe pump, in an enclosure with controlled ambient humidity and temperature. The power supply provided a constant voltage, $30 \mathrm{kV}$, between the tip of the grounded spinneret needle (size 18G) and the rotating collector. The latter, a drum rotating at $1000 \mathrm{RPM}$, was placed at a distance of $13 \mathrm{~cm}$ from the needle tip. The actual nano-fibre mat was collected on a non-stick aluminum foil wrapped around the metal drum. Electrospun mats were first dried in ambient air for ca. 3 days, then cut into pieces and carefully peeled from the aluminum foil for subsequent experiments. The pieces of scaffolds were stored in a desiccator until further use. Process conditions are summarized in Table 1. 
Table 1 Process conditions used to produce the present electrospun aligned PET mats.

\begin{tabular}{|c|c|c|c|c|c|c|c|c|c|c|}
\hline \multirow{3}{*}{$\begin{array}{l}\text { Polymer solution } \\
\text { concentration } \\
(\% \mathrm{w} / \mathrm{v})\end{array}$} & \multicolumn{4}{|c|}{ Process parameters } & \multicolumn{4}{|c|}{ Collector } & \multicolumn{2}{|c|}{$\begin{array}{l}\text { Ambient } \\
\text { conditions }\end{array}$} \\
\hline & \multirow[b]{2}{*}{$\begin{array}{l}\text { Needle } \\
\text { size (G) }\end{array}$} & \multirow[b]{2}{*}{$\begin{array}{l}\text { Tip-Collector } \\
\text { distance }(\mathrm{cm})\end{array}$} & \multirow[b]{2}{*}{$\begin{array}{c}\text { Voltage } \\
(\mathrm{kV})\end{array}$} & \multirow{2}{*}{$\begin{array}{l}\text { Flow } \\
\text { rate } \\
(\mathrm{mL} / \mathrm{h})\end{array}$} & \multicolumn{2}{|c|}{ Dimension } & \multicolumn{2}{|c|}{ Speed } & \multirow[b]{2}{*}{$\begin{array}{l}\text { RH } \\
(\%)\end{array}$} & \multirow[b]{2}{*}{$\begin{array}{c}\text { Temp. } \\
\left({ }^{\circ} \mathrm{C}\right)\end{array}$} \\
\hline & & & & & $\begin{array}{l}\text { Length } \\
\text { (cm) }\end{array}$ & $\begin{array}{c}\text { Radius } \\
\text { (cm) }\end{array}$ & $\begin{array}{c}\text { velocity } \\
(\mathrm{m} / \mathrm{s})\end{array}$ & RPM & & \\
\hline 12.5 & 18 & 13 & 30 & 10 & 35 & 10 & 10.3 & 1000 & $8-25$ & $20-25$ \\
\hline
\end{tabular}

\subsubsection{Plasma Etching}

\subsubsection{Low-Pressure}

Nano-fibre mats were etched in a low-pressure ("LP") capacitively coupled radio-frequency (r.f., 13.56 MHz) glow discharge plasma reactor[37], using (i) Argon (Ar) / 10\% Oxygen $\left(\mathrm{O}_{2}\right)$ gas mixture, or (ii) pure oxygen $\left(\mathrm{O}_{2}\right)$ (both from Air Liquide Canada Ltd., Montreal, QC). Etch treatments were performed at 100 milliTorr $(13.3 \mathrm{~Pa})$ pressure in the cylindrical aluminum/steel reactor chamber, flows of the feed gases being controlled using electronic flow meter/controllers (Vacuum General Inc., San Diego, CA), and admitted into the chamber via a shower-head gas distributor of $10 \mathrm{~cm}$ diameter. The flow rate of gas was kept constant at 20 standard cubic centimeters per minute (sccm) for both cases (i) and (ii) above. The treatment was performed at constant power, $P=50 \mathrm{~W}$ (corresponding d.c. bias voltage, $V_{B}=-40 \mathrm{~V}$ ), for different durations, namely $3,6,12$, and 15 minutes, samples being placed on the $(10 \mathrm{~cm}$ diameter) powered electrode. Clearly, the maximum energy of ions impinging on the samples' surfaces, a key parameter in plasma etching, did not exceed some tens of $\mathrm{eV}$, as indicated by the above-cited value of $V_{B}$. In reference 18 we pointed out that at this low pressure, active plasma species can penetrate through the entire depth of the highly porous mats.

\subsubsection{Atmospheric Pressure}


The high-("HP", atmospheric)-pressure dielectric barrier discharge (DBD) apparatus was described and illustrated earlier, and it was operated in atmospheric air in the so-called corona mode [38, 39]. Briefly, the system comprised a cylindrical, dielectric-coated stainless steel highvoltage (HV) electrode and a grounded, planar Al electrode on which reposed a $300 \times 240 \mathrm{~mm}^{2}, 2$ mm-thick glass plate that served both as substrate and as a second dielectric layer (the gap between the two was typically $1 \mathrm{~mm}$ ). The lower (planar) electrode and glass plate were moved back and forth under the HV electrode at precisely controlled speed, depending on the desired treatment (etching) time. The roughly $1 \mathrm{~cm}$ wide plasma (filamentary corona) zone was generated with a commercial power source and transformer (Enercon Industries, model LM2727-03, 450 kVA maximum output) at a typical frequency of $10 \mathrm{kHz}$ and peak-to-peak voltage of $18 \mathrm{kV}$.

\subsubsection{Plasma Asher}

A low-pressure microwave plasma ashing system (GIGAbatch 360 M, PVA TePla A.G., Germany), designed to remove organic photoresist during the manufacture of integrated circuits, was also used here to etch nanofibrous PET mats. The density of microwave plasma, ca. $10^{11} \mathrm{~cm}^{-3}$, is much greater than that of its r.f. counterpart, typically $10^{9} \mathrm{~cm}^{-3}$, resulting in a greatly increased etch rate $[40,41]$. As in earlier work $[40,41]$ (i) a mixture of $\mathrm{O}_{2} / 20 \% \mathrm{CF}_{4}$, but also (ii) pure $\mathrm{O}_{2}$ were used at $1000 \mathrm{mTorr}(133.3 \mathrm{~Pa}$ ) pressure, and at $200 \mathrm{~W}$ of microwave power for 1 min and 5 min, respectively. The optimal etching conditions, ones presumably leading to highest yields of $\mathrm{O}$ and $\mathrm{F}$ atoms, were taken from previously published research by this laboratory [41].

\subsection{Materials Characterization}

\subsubsection{Scanning Electron Microscopy (SEM)}

Selected samples were examined by field-emission scanning electron-microscopy (FE-SEM) using a JEOL model JSM-7600 TFE instrument (JEOL Ltd., Tokyo, Japan) at a voltage of $1 \mathrm{kV}$ and a working distance of $13.3 \mathrm{~mm}$, at different magnifications. Nano-fiber mat surfaces were sputter-coated under vacuum with a thin layer of gold in a dedicated coater for 50 seconds, and were then mounted on a suitable sample holder using double-sided tape. The diameters and diameter distributions of 400 randomly-selected fibers (at least two experiments with triplicate 
samples of both pristine and etched mats) were examined by SEM. Micrographs were analyzed using image analysis software (NIH Image software).

\subsubsection{Mat Thickness}

The mats' thicknesses were measured using a digital gauge (Film Master, Qualitest, designed for film thickness measurements with better than $10 \mu \mathrm{m}$ resolution). To minimize possible error resulting from compression of the mats during measurements, they were sandwiched between two rigid PET films.

\subsubsection{Quantification of Fiber Alignment}

Fast Fourier Transform (FFT) was used to characterize the alignment of the fibers. Here, we merely present the essentials, because details have been described elsewhere [42, 43]. The FFT function converts spatial information into an optical data image in a mathematically defined frequency domain. The resulting FFT output image reflects the degree of fiber alignment present in the selected area. A square region of $512 \times 512$ pixels on the SEM image was randomly selected and processed for FFT using image analysis software (NIH Image software) supported by an oval profile plug-in. All FFT data was normalized to a baseline value of 0 and plotted in arbitrary units, allowing different data sets to be directly compared.

\subsubsection{Porosity}

Porosity properties of nanofiber mats were determined using a liquid (ethanol) intrusion method $[44,45]$. Dry mats were weighed before being immersed in $100 \%$ ethanol overnight for complete wetting. Mats were then gently wiped to remove excess ethanol and weighed again. Porosity is defined as the volume of the ethanol entrapped in the pores divided by the total volume of the wet mats (ethanol + mat). In our previous study,[19] we also measured porosity of mats by two other alternative methods, namely gravimetric and mercury intrusion porosimetry. It is worth noting that they gave similar results, with no significant difference compared with the liquid (ethanol) intrusion method. 


\subsubsection{X-Ray Photoelectron Spectroscopy}

X-Ray photoelectron spectroscopy (XPS) analyses were performed in a VG ESCALAB 3MkII instrument, using non-monochromatic $\mathrm{Mg} \mathrm{K \alpha}$ radiation. The size of the analyzed area was about $1 \mathrm{~mm}^{2}$, the sampling depth being in the 1-5 nm range on account of the fibers' geometries. Spectra were acquired at $0^{\circ}$ emission angles (normal to the mat surface), and charging was corrected by referencing all peaks to the carbon $(\mathrm{C} 1 \mathrm{~s})$ peak at binding energy, $B E=285.0 \mathrm{eV}$. The $\mathrm{X}$-ray source was operated at $15 \mathrm{kV}, 20 \mathrm{~mA}$. Quantification of data was performed using Avantage v4.12 software (Thermo Electron Corporation) by integrating the area under a specific peak after a Shirley-type background subtraction, and using sensitivity factors from the Wagner table. Data acquired by XPS survey spectra were combined to calculate $[\mathrm{O}],[\mathrm{O}] /[\mathrm{C}]$, and other quantities of interest.

\subsubsection{Static Contact Angle (SCA) Measurements}

Static contact angle (SCA) of water was measured using a VCA Optima Surface Analysis System (AST Products, Billerica, MA) at room temperature (approximately $23^{\circ} \mathrm{C}$ ). The sample was fixed on a glass slide, a $2 \mu \mathrm{L}$ drop of MilliQ water was placed on the sample surface using a microsyringe, and SCA was measured using the VCA software provided by the manufacturer. The measurement was repeated at five different locations on selected samples; each experiment was carried out in triplicate to ensure reproducibility, the values were averaged, and the standard deviation was calculated.

\subsubsection{Wicking Properties}

Since the nanofiber mats possess irregular structure with high porosity, it is difficult to precisely measure the wetting properties by contact angle measurements. As an alternative, wicking behavior of the mats can provide sufficiently accurate information about the wetting behaviour. According to the ISO9073-6 standard test method, wicking can be expressed as the height of capillary rise measured for a predetermined time, or the time required for a liquid to reach a predetermined height. We measured the time of capillary rise to $2 \mathrm{~cm}$ height in a vertically 
suspended specimen strip $(2 \mathrm{~cm} \times 1 \mathrm{~cm})$ along the fiber direction, while the lower end was dipped into water colored with methylene blue.

\subsubsection{Tensile Testing}

Tensile properties of the mats were evaluated using a uniaxial tensile testing machine (Instron, ElectroPuls ${ }^{\mathrm{TM}}$ E3000). Samples were prepared by cutting mats into $0.5 \mathrm{~cm}$ x $2 \mathrm{~cm}$ strips; a given sample was then inserted into the Instron's jaws, the distance between the upper and the lower jaw being set at $1 \mathrm{~cm}$. The tensile test was performed using a $250 \mathrm{~N}$ load cell, at a controlled rate of 10 $\mathrm{mm} / \mathrm{min}$. Young's modulus, yield strength, yield strain, tensile strength and elongation at break were calculated manually using Stress-Strain curves. Samples were tested in the "dry" state (in ambient air). Experiments were repeated three times; at least 12 samples were used in each experiment to test reproducibility.

\subsubsection{Low-cycle Strain-controlled Accelerated Fatigue Testing}

In addition, low-cycle strain-controlled fatigue testing was carried out on the samples which had the closest mechanical properties to those of natural arteries (ePET-Asher- $\mathrm{O}_{2}-5 \mathrm{~min}$, see further below). Pristine and plasma-etched samples were cut into strips $(6 \mathrm{~mm} \times 20 \mathrm{~mm})$, and placed between the grips of a uniaxial tensile tester (Bose, Electroforce 3200 instrument, $22 \mathrm{~N}$ load cell). Cyclic uniaxial tensile testing was performed in the elastic domain with a strain-controlled loading (initial linear part of the stress-strain curve, see below). Mat-samples were stretched using a cross-

head speed of $0.17 \mathrm{~mm} / \mathrm{s}$ to an initial strain of $0.25 \%$ (pre-conditioning), and were then subjected to $1,000,000$ continuous sinusoidal cycles at $10 \mathrm{~Hz}$, in strain ranges of $\pm 1 \%$, whereby the maximum strain, $\varepsilon_{\max }$, did not exceed the yield strain.

\subsubsection{Intrinsic Viscosity and Molecular Weight}

Solution viscosity measurements were performed with pristine and plasma-etched ePET samples, to determine their intrinsic viscosity and molecular weight $[46,47]$. In accordance with ASTM-D 4603, a Cannon-Ubbelohde viscometer was used for this purpose: A solvent mixture of phenol / 1,1,2,2-tetrachloroethane $(60 / 40 \mathrm{w} / \mathrm{w})$ was employed to dissolve $0.125 \mathrm{~g}$ of the PET samples in 25 
$\mathrm{mL}$ of solvent at $110^{\circ} \mathrm{C}$ for $1 \mathrm{hr}$. Once the samples were completely dissolved, the solutions were first filtered, then tested at $30{ }^{\circ} \mathrm{C}$ in a water bath, as follows: From the flow times of the pure solvent mixture $\left(\mathrm{t}_{0}\right)$ and the polymer solutions ( $\mathrm{t}$, at least three measurements), inherent and intrinsic viscosities were determined from the following equations:

$$
\eta_{\text {inh }} \quad{ }_{0.5 \%} 30^{\circ} C=\frac{\ln \eta_{r}}{C}
$$

where:

$$
\begin{aligned}
& \eta_{i n h}{ }_{0.5 \%}^{30^{\circ} \mathrm{C}} \text { : inherent viscosity at } 30^{\circ} \mathrm{C} \text { and at polymer concentration of } 0.5 \mathrm{~g} / \mathrm{dL} \\
& \eta_{r}: \text { relative viscosity }=\mathrm{t} / \mathrm{t}_{0} \\
& \mathrm{t}: \text { average solution flow time, } \mathrm{s} \\
& \mathrm{t}_{0}: \text { average solvent flow time, } \mathrm{s} \\
& \mathrm{C}: \text { polymer solution concentration, } \mathrm{g} / \mathrm{dL}
\end{aligned}
$$

The intrinsic viscosity was calculated by using the Billmeyer relationship:

$$
\eta=0.25\left(\eta_{r}-1+3 \ln \eta_{r}\right) / C
$$

By means of the Mark-Houwink equation, it is possible to determine the viscosity molecular weight, $\mathrm{M}_{\mathrm{v}}$, from the above-calculated intrinsic viscosity:

$$
[\eta]=K M_{v}^{a}
$$

where the constants " $\mathrm{K}$ " and "a" at $30^{\circ} \mathrm{C}$ are $2.37 \times 10^{-4}$ and 0.73 , respectively [47].

\subsubsection{Differential Scanning Calorimetry (DSC)}

Melting and crystallization behaviors of pristine and plasma-etched samples were carried out in pure nitrogen atmosphere using a differential scanning calorimeter (Model Q2000, TA Instruments Co., New Castle, DE, USA) equipped with a universal analysis 2000 program (Model Q1000, TA Instruments). About $10 \mathrm{mg}$ of polymer was weighed and crimped into an aluminum pan; then, a heat-cool-heat programming protocol was used with a rate of $10^{\circ} \mathrm{C} \mathrm{min}{ }^{-1}$ over the temperature range from $30^{\circ} \mathrm{C}$ to $300^{\circ} \mathrm{C}$, that was expected to include crystallization, melting and glass 
transitions of all samples. Heat flow and temperature were calibrated using an indium metal standard.

\subsection{Biological Testing}

\subsubsection{Cell Culture and Seeding}

Vascular smooth muscle cells (VSMCs) from rat embryonic thoracic aorta (a7r5 cell line, ATCC, Manassas, VA) cultured in Dulbecco's Modified Eagle's Medium/ Nutrient Mixture F-12 Ham's Media (DMEM/F12; Invitrogen, Burlington, ON) supplemented with 10\% fetal bovine serum (FBS; Medicorp, Montreal, QC) were used between passages 4 to 15. Samples from pristine and plasma-etched electrospun mats (Asher- $\mathrm{O}_{2} ; 5 \mathrm{~min} ; \mathrm{n}=6$ each) were cut into disks with a punch $(D$ $=1 \mathrm{~cm}$ ), placed into 48 -well polystyrene culture plates, sterilized in $70 \%$ ethanol for $5 \mathrm{~min}$, followed by a rinse with sterile water. Samples were dried overnight under a laminar hood. Next day, cloning glass cylinders $(0.8 \mathrm{~cm}$ inner diameter; $1 \mathrm{~cm}$ height $)$ were placed on the samples to prevent cell adhesion on the outside. VSMCs were detached with $0.05 \%$ trypsin/EDTA (Invitrogen, 25300-054), counted and diluted to obtain a suspension of 100,000 cells/ml. Next, 200 $\mu \mathrm{L}$ of this suspension (20,000 cells) was added to each well. As control, cells were also cultured directly on polystyrene culture plates (hereafter "PCP"). After a $24 \mathrm{~h}$ culture period, cloning cylinders and medium were removed, and $500 \mu \mathrm{L}$ of fresh complete medium was added to each well. The plates were incubated for 1 and 7 days, the culture medium (DMEM/F12 supplemented with $1 \%$ penicillin-streptomycin (Pen-Strep; Invitrogen) being changed every 2 days.

\subsubsection{Cell Adhesion and Growth}

\subsubsection{AlamarBlue Assay}

Cell adhesion and growth was assessed using AlamarBlue reduction assay (Cedarlane, 300251(BT)), during which cell metabolic activity reduces resazurin dye (blue) to resorufin (pink). At days 1 and 7, culture medium was removed and $500 \mu \mathrm{L}$ of complete medium plus $50 \mu \mathrm{L}$ of AlamarBlue were added to each well and incubated for $4 \mathrm{~h}$ at $37{ }^{\circ} \mathrm{C}, 5 \% \mathrm{CO}_{2}$. After $4 \mathrm{~h}, 150-\mu \mathrm{L}$ aliquots were pipetted into 96-well plates (Corning) in triplicate, and the plates were examined at excitation/emission wavelengths of 560/590 $\mathrm{nm}$ in a fluorescence plate reader (BioTek, Synergy 
4). The experiment was repeated three times to assure reproducibility. To confirm these data, the density and homogeneity of cells on the mats were directly observed after staining cells by crystal violet solution $(0.075 \% \mathrm{w} / \mathrm{v}$ in a $3 \% \mathrm{v} / \mathrm{v}$ acetic acid solution) for $15 \mathrm{~min}$, rinsed 3 times with MilliQ water and air-dried prior to capture by microscopy (not shown here).

\subsubsection{2. $\quad$ Scanning Electron Microscopy (SEM)}

To visualize cell morphology on controls and plasma-etched scaffolds, some samples with cells grown for 7 days were fixed at room temperature for $1 \mathrm{hr}$ with $3 \%$ glutaraldehyde (diluted in PBS), before rinsing twice with PBS. Thereafter, they were dehydrated in successive ethanol solutions of different concentrations (30, 50, 70, 95 and twice 100\%; 10 min each). Samples were air-dried under a hood overnight, then gold-coated (Coater: Emitech, K550X) for 2 min for SEM observation (Hitachi, S-3600N).

\subsubsection{Statistical Analysis}

All data are expressed as mean values \pm SD. Statistical analysis was carried out using independent t-test when comparing two groups only (for example, pristine versus plasma-etched). Values of $p$ lower than 0.05 were considered significant for all tests.

\section{Results and Discussion}

\subsection{Physical Properties of Pristine and of Etched Samples}

\subsubsection{Fiber Alignment and Mat Thickness}

Partially aligned nanofibrous PET mats were prepared by electrospinning, the mandrel being rotated at $1000 \mathrm{rpm}$. The height and shape of the 2D FFT plot derived from an SEM micrograph of a pristine mat bear witness to a high degree of fiber alignment (Figure $1 \mathbf{A , B}$ ): The higher and narrower the peak, the more precisely aligned are the fibers along a single direction. The frequency plot, Figure 1C, shows greatest intensity in the direction of fiber orientation on the micrograph, 
while sharp peaks near $90^{\circ}$ and $270^{\circ}$ confirm that the vast majority of fibers were preferentially oriented in the direction of mandrel rotation, that is, perpendicular to the axis of rotation.
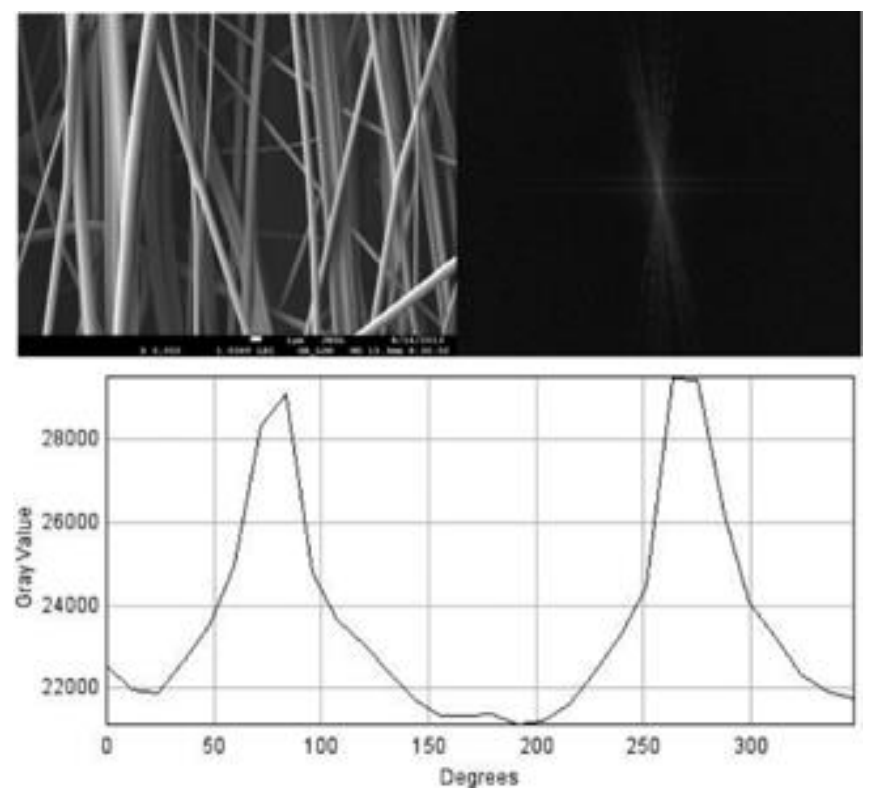

Figure 1 Two-dimensional FFT analysis of scaffold anisotropy; (A) SEM micrograph of pristine aligned electrospun nanofiber sample; (B) Image frequency plot; (C) 2D FFT alignment plot for the corresponding SEM micrograph.

Mat thickness measurements revealed significant variation from the center to the edges (70-100 $\mu \mathrm{m})$. Therefore, samples for later experiments were taken exclusively from the central portions.

\subsubsection{Measurements of Pore Parameters and Porosity}

Porosity results from pristine and plasma-etched samples (Table 2) were obtained by ethanol intrusion porosimetry. The high porosity of pristine mats, $78 \%$, is highly desirable for the intended media layer of vascular grafts, readily enabling the transport of nutrients, metabolic wastes and gases. Moreover, the pore size is large enough to allow SMC penetration into the scaffold. As expected, the porosity was seen not to change significantly after plasma etching. 
Table 1 Average fiber diameter and porosity of electrospun mats, pristine and plasma-etched.

\begin{tabular}{|c|c|c|}
\hline $\begin{array}{l}\text { Sample } \\
\text { (etch time) }\end{array}$ & $\begin{array}{l}\text { Average fiber } \\
\text { diameter [nm] }\end{array}$ & $\begin{array}{c}\text { Porosity } \\
\text { (\%) }\end{array}$ \\
\hline Pristine ePET & $890 \pm 350$ & 78 \\
\hline $\mathrm{LP}-\mathrm{Ar}-\mathrm{O}_{2}$ (15 min) & $690 \pm 430^{\mathrm{a})}$ & 75 \\
\hline $\mathrm{LP}^{-\mathrm{O}_{2}}$ (15 min) & $770 \pm 340^{\mathrm{a})}$ & 74 \\
\hline HP-Corona (15 min) & $720 \pm 350^{\mathrm{a})}$ & 77 \\
\hline Asher- $\mathrm{O}_{2}(5 \mathrm{~min})$ & $830 \pm 395^{a)}$ & 76 \\
\hline Asher- $\mathrm{O}_{2}-\mathrm{CF}_{4}(1 \mathrm{~min})$ & $670 \pm 350^{\mathrm{a})}$ & 78 \\
\hline
\end{tabular}

\subsubsection{Scanning Electron Microscopy (SEM)}

SEM micrographs of untreated and plasma-etched samples are shown in Figure 2; all are seen to possess structures with large open spaces. The pristine mats clearly show smooth fibers with diameters ranging between 400 and $2000 \mathrm{~nm}$, the average value being $890 \pm 350 \mathrm{~nm}$. Average fiber diameters for plasma-etched samples are shown in Table 2: After $\mathrm{O}_{2}$ and $\mathrm{Ar} / 10 \% \mathrm{O}_{2}$ "LP"-type plasma etching, one notes reduced diameters accompanied by progressively rougher surface features for shorter treatment times (up to12 $\mathrm{min}$ ), while longer-duration (15 $\mathrm{min}$ ) exposure caused degradation of the fiber structure and increased friability of the mats. In the case of "HP" (corona) discharge, surface roughening in the form of tiny pits and micro-cracks accompanied a reduction in the average fiber diameter after 15 min. exposure (Table 2). For both "LP" and "HP"-treated samples the density, depths and sizes of pits and micro-cracks increased with rising exposure time. In the case of "LP", vacuum ultraviolet (VUV) radiation $(\lambda<200 \mathrm{~nm})$ and ion bombardment may have contributed, in addition to erosion by reactive oxygen species. Somewhat surprisingly, the plasma-asher was found not to significantly alter the fibers' morphology, while nevertheless significantly reducing the average fiber diameter (Table 2). We did not investigate longer treatment durations with the plasma asher, because 1 or $5 \mathrm{~min}$ of exposure was sufficient to adequately reduce the mechanical properties (see below). 
The influence of plasma etching on porosity is only minor, but etching clearly leads to fiber diameter reduction, changes to fiber texture and to network morphology. It is worth pointing out that some similar observations had already been reported in earlier literature, notably preferential etching of small-diameter fibers [32], and surface roughening [32-34].

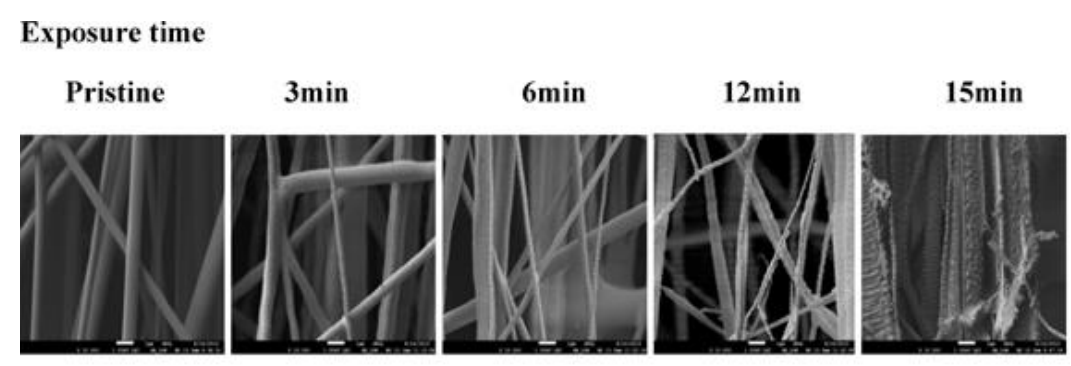

A) $\mathrm{O}_{2}$ "LP"-type plasma etching
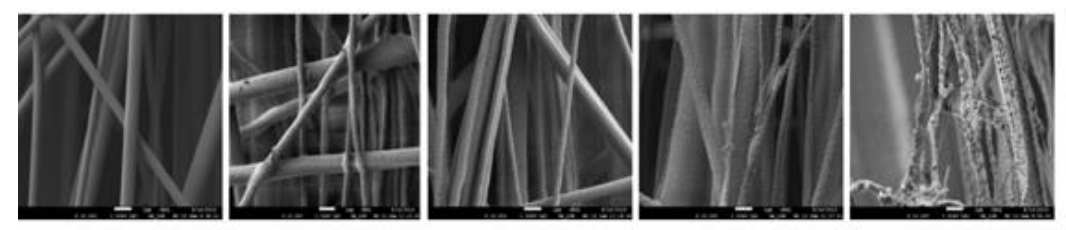

B) $\mathrm{Ar} / 10 \% \mathrm{O}_{2}$ "LP"-type plasma etching
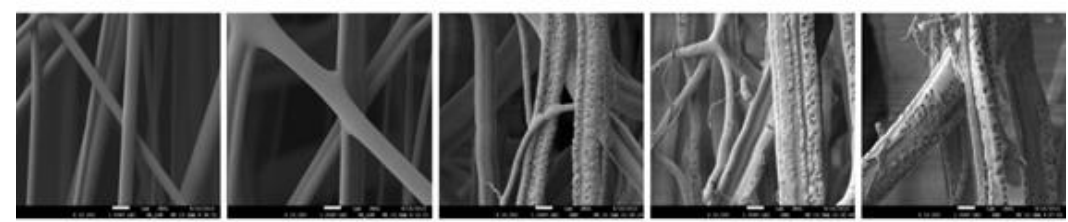

C) "HP" corona discharge

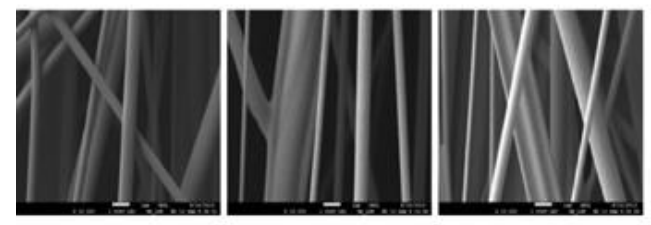

D) Pristine Asher $\mathrm{O}_{2}(5 \mathrm{~min}) \quad$ Asher $\mathrm{O}_{2} / 20 \% \mathrm{CF}_{4}(1 \mathrm{~min})$

Figure 2 SEM micrographs of electrospun aligned PET nano-fiber mats; effects of different plasma-etch treatment processes: (A) O2 "LP"-type plasma etching; (B) $\mathrm{Ar} / 10 \% \mathrm{O} 2$ "LP"-type plasma etching; (C) "HP" corona discharge; D) Plasma-asher (scale bar: $1 \mu \mathrm{m}$ ). 


\subsubsection{Surface-Chemical (XPS) Analyses}

The surface-chemical compositions of pristine and plasma-treated mats were obtained by XPS analyses, Table 3 Surface-near C and O concentrations of pristine samples were $70.5 \%$ and 29.5 $\%$, respectively, but plasma-etched ones displayed higher $\mathrm{O} / \mathrm{C}$ ratios, as expected. "LP"-type $\mathrm{O}_{2}$ plasma etching led to higher $\mathrm{O} / \mathrm{C}$ than its $\mathrm{Ar}-10 \% \mathrm{O}_{2}$ counterpart, while "HP" corona created mostly $\mathrm{O}$-containing groups, but some $\mathrm{N}$ - containing ones, as well. Plasma ashing, on the other hand, resulted in the highest $\mathrm{O} / \mathrm{C}$ ratio. This is presumably caused by very high atomic oxygen content in the microwave-excited plasma. Plasma-ashing with the $\mathrm{O}_{2} / 20 \% \mathrm{CF}_{4}$ mixture was found to result in low F concentration at the surface.

Table 3 Surface-chemical compositions of pristine and plasma-etched electrospun mats.

\begin{tabular}{lccccc} 
& C1s & O1s & N1s & F1s & {$[\mathrm{O}] /[\mathrm{C}]$} \\
\hline ePET (pristine) & 70.5 & 29.5 & - & - & 0.4 \\
$\mathrm{LP}-\mathrm{Ar}-\mathrm{O}_{2}(15 \mathrm{~min})$ & 65.4 & 34.7 & - & - & 0.5 \\
$\mathrm{LP}-\mathrm{O}_{2}(15 \mathrm{~min})$ & 62 & 38 & - & - & 0.6 \\
$\mathrm{HP}$ Corona $(15 \mathrm{~min})$ & 64 & 34.5 & 1.5 & - & 0.5 \\
Asher- $\mathrm{O}_{2}$ (5 min) & 52.8 & 47.2 & - & - & 0.9 \\
Asher- $\mathrm{O}_{2}-\mathrm{CF}_{4}(1 \mathrm{~min})$ & 54.8 & 40.5 & - & 4.8 & 0.7
\end{tabular}

\subsubsection{Contact Angle (SCA) Measurements}

The water SCA results are summarized in Table 4. It can be clearly seen that plasma etching dramatically changes the surface response from hydrophobic to fully hydrophilic $\left(\sim 0^{\circ}\right)$. The water droplets spread and immediately penetrated into all plasma-etched mats once they were placed on the surfaces. This can be due to capillary effects, surface roughness, porosity and high surface oxygen content as seen from XPS data (Table 3), which can be mainly assigned to polar carbonyl and carboxyl groups. 


\subsubsection{Wicking Properties}

As explained earlier, SCA measurements alone do not enable one to fully understand the hydrophilicity of nanofibrous materials. Therefore, wicking was proposed as a complementary method of investigation. Wicking is the spontaneous uptake of a liquid into a porous substrate, driven by capillary forces. Table 4 presents the wicking time for a $2 \mathrm{~cm}$ liquid rise in plasmaetched ePET mats, compared with the pristine "non-wetting" one, for which no capillary rise was observed. This supports SCA measurements, which showed that plasma etching significantly increased the wettability of electrospun PET mats.

Table 4 Static contact angle and wicking time of pristine and plasma-etched electrospun mats.

\begin{tabular}{lcc} 
& $\begin{array}{c}\text { Static Contact } \\
\text { Angle }\left({ }^{\circ}\right)\end{array}$ & Wicking time (s) \\
\hline ePET & $137 \pm 3$ & N.A. (non-wetting) \\
$\mathrm{LP}-\mathrm{Ar}-\mathrm{O}_{2}$ & 0 & 4.5 \\
$\mathrm{LP}-\mathrm{O}_{2}$ & 0 & 5 \\
$\mathrm{HP}$ Corona & 0 & 8.5 \\
Asher- $\mathrm{O}_{2}$ & 0 & 8.5 \\
Asher $-\mathrm{O}_{2}-\mathrm{CF}_{4}$ & 0 & 9
\end{tabular}

\subsection{Tensile Tests}

The tensile properties of pristine and plasma-etched mats were measured in the length direction of the $0.5 \mathrm{~cm} \times 2 \mathrm{~cm}$ sample strips. The effects of plasma etching by "LP, "HP" and asher at different treatment times are depicted in Figure 3 and Figure 4; the latter also shows selected literature data for ePET after $\mathrm{NaOH}$ wet-chemical etching [15], and for femoral artery [48], for comparison. Young's modulus, tensile strength and elongation at break were all found to decrease significantly with rising treatment time (Figure 3). Interestingly, shorter treatment times sufficed for the plasma asher to achieve similar reduction in Young's modulus as with LP and HP plasma (Figure 4). For this reason, no longer treatment duration was investigated with plasma asher. We had noted earlier that LP and HP plasma etching both introduced micro-pit surface defects, and that they led to fiber degradation after longer exposure times (see Figure 2). Thus, observed decreases in tensile 
properties with rising treatment times are not unexpected. Surprisingly, as also noted earlier, micro-pits and -cracks were not observed on fibers treated in the plasma asher, even though the PET erosion rate was high [40, 41], especially for $\mathrm{O}_{2}-\mathrm{CF}_{4}$ etch (Table 2). Here too, plasma etching resulted in significant decrease in Young's modulus, tensile strength and elongation at break. These might be due to more intense short-wavelength VUV irradiation in the microwave plasma, resulting in more chain scissions. This may be particularly significant for the present highly porous nano-fibrous mats, because plasma can be sustained inside the pores and VUV can affect a significant fraction of the fibers' volume in spite of its shallow penetration depth (a few tens of nm [29, 49-51]). To further examine possible chain scission effects, intrinsic viscosity and molecular weight measurements were carried out; the results are discussed in the following section.

Young's modulus was calculated from the linear portion of the stress-strain curve, and data are presented in comparison with values from the literature. Young's moduli and tensile strengths of plasma-etched PET mats are comparable to those of natural arteries (see Figure 4). On the other hand, elongation at break was found to be less than that of arteries in all cases. However, even though uni-axial tensile testing allows one to assess elastic properties of the fabricated scaffolds, it does not provide a direct measure of compliance (a multi-axial property). Therefore, further tests are desirable, particularly ones designed to evaluate compliance and fatigue resistance of tubular multilayered graft prototypes; this is the subject of ongoing work. 

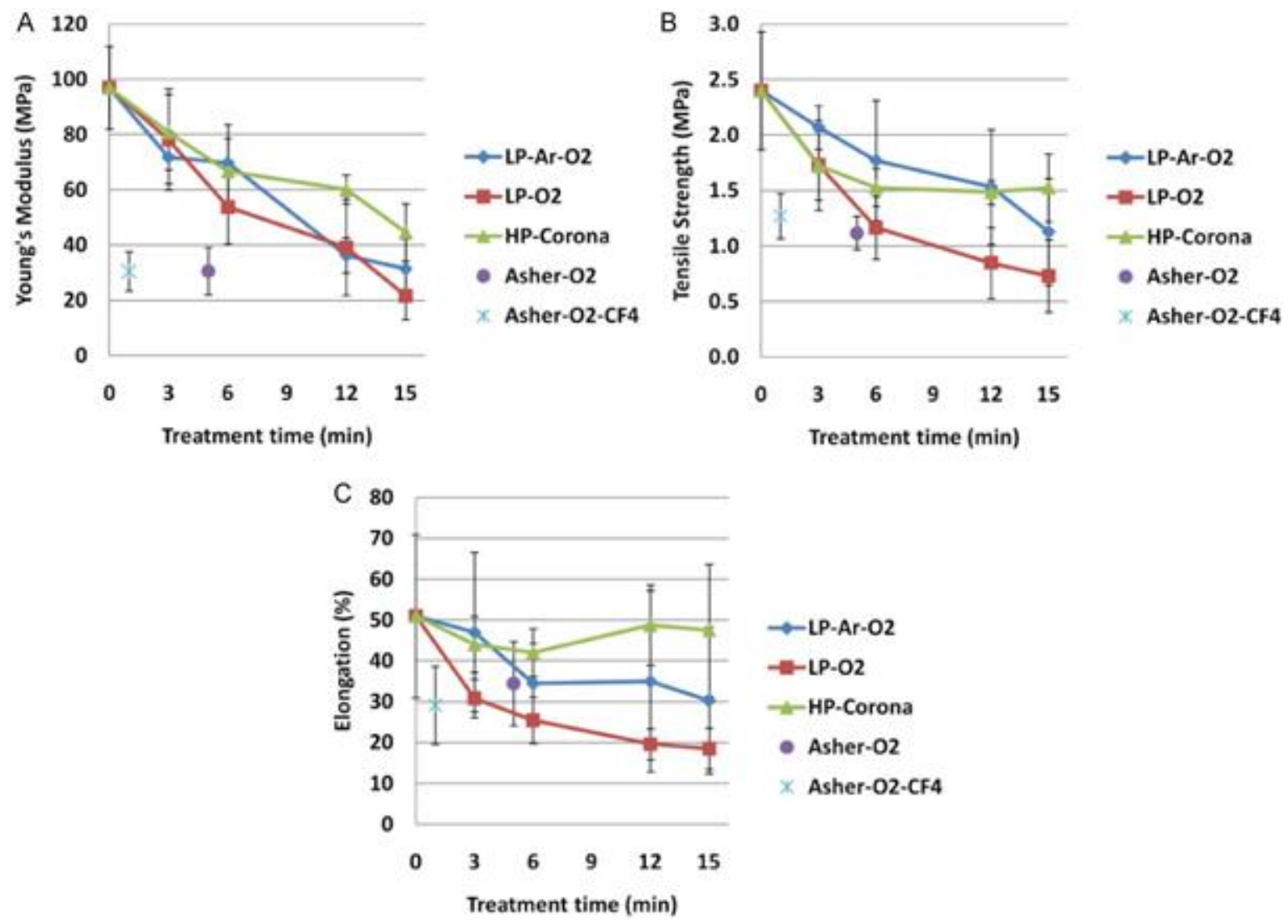

Figure 3 Effect of etch duration on mechanical properties of pristine and plasma-etched aligned ePET mats (three experiments, at least 12 samples in each experiment). (A) Young's modulus; (B) tensile strength; (C) elongation at break. 

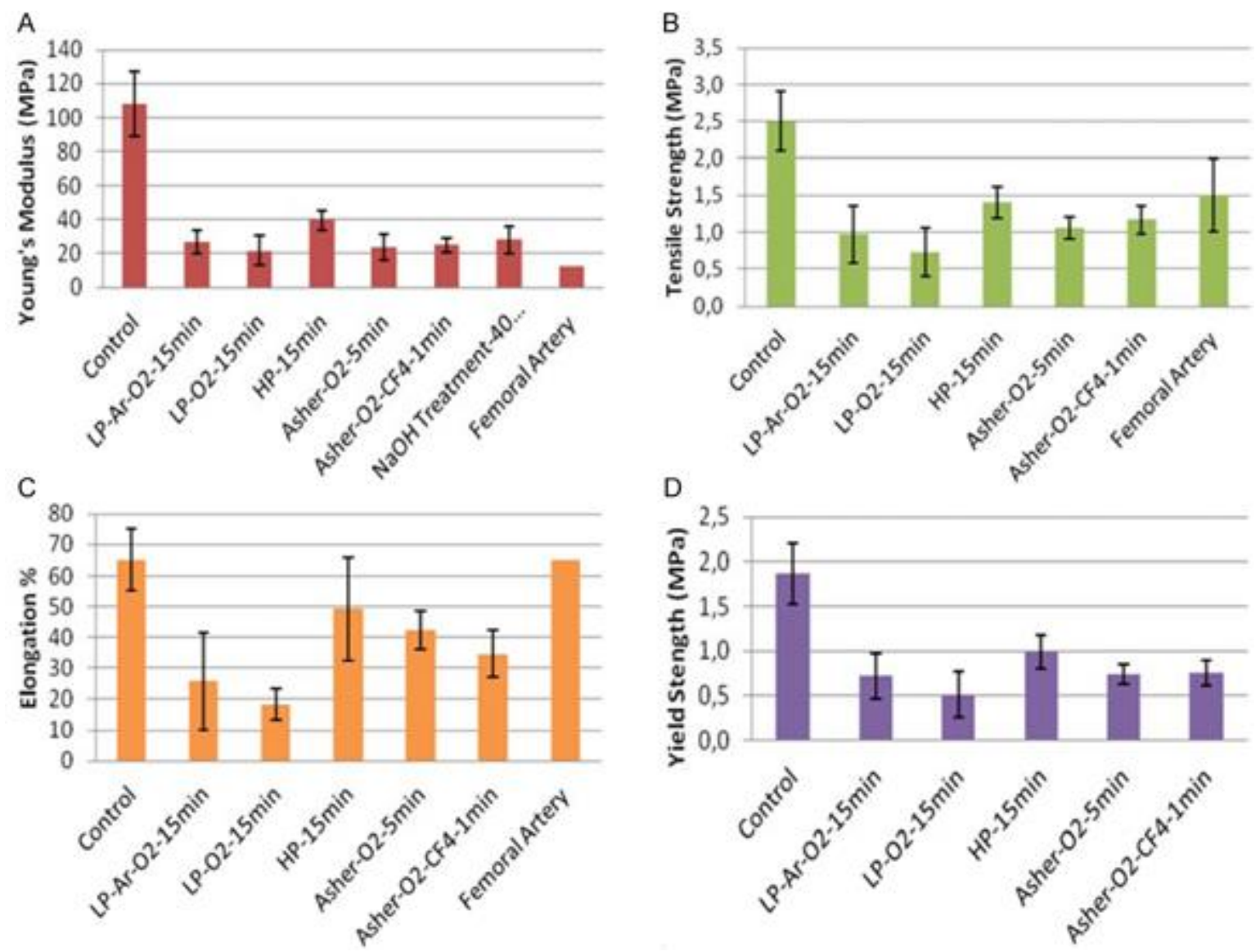

Figure 4 Mechanical properties of pristine and plasma-etched aligned ePET mats (three experiments, at least 12 samples in each experiment). (A) Young's modulus; (B) tensile strength; (C) elongation at break; (D) yield strength. Yield strain did not change significantly for plasmaetched samples compared with pristine ones.

\subsubsection{Low-cycle strain-controlled accelerated fatigue testing}

For further experiments, an asher-etched ePET mat (Asher- $\left.\mathrm{O}_{2}, 5 \mathrm{~min}\right)$ was chosen, because it provides similar reduction of Yong Modulus as other etch treatments, but for short treatment duration, no significant alteration of the fibers' morphology and no F content. Stress-strain curves $\left(\mathrm{N}=1 ; 1,000,000\right.$ cycles) of pristine ePET and of mats etched with the plasma-asher (Asher- $\left.\mathrm{O}_{2}\right)$ are depicted in Figure 5. The loading / unloading curves did not change with increasing numbers of cycles. Therefore, after a large number of $10 \mathrm{~Hz}$ cycles the samples' mechanical properties were unchanged, which is of course highly desirable for the application considered in this study. In addition, some minor hysteresis (a possible difference between loading and unloading, which 
represents energy loss in the system) did not significantly change with the number of cycles at this frequency, as evidenced by the constant area between loading and unloading curves. No signs of sample damage (buckling and deformation) were observed during experiments. However, while fatigue testing of planar mats does allow one to assess fatigue behavior, more detailed studies on tubular multilayered prototype grafts will be desirable to understand their behavior in the real applications.

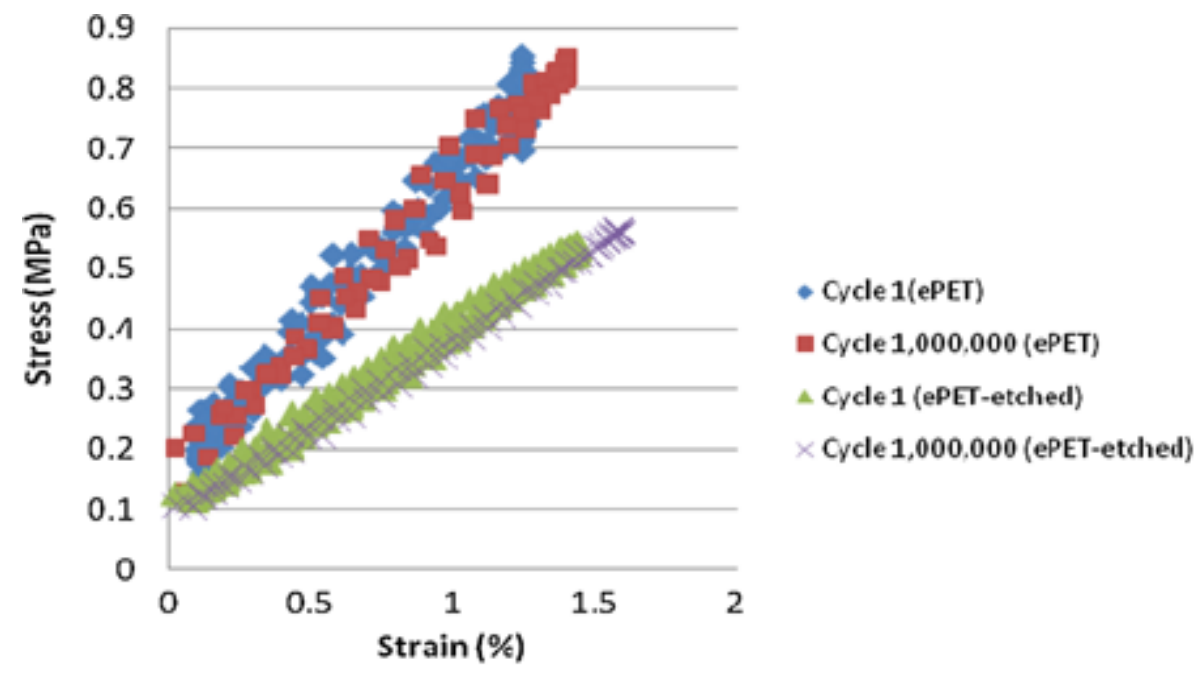

Figure 5 Strain-stress diagrams (loading and unloading) for pristine and plasma-etched aligned ePET mats, at cycle numbers 1 and 1000000.

\subsubsection{Intrinsic Viscosity and Molecular Weight}

In the preceding section, we postulated that plasma etching might entrain chain scissions, leading to lower average chain lengths (reduced molecular weight). This might originate from both ion bombardment (LP-type plasma) and VUV irradiation, for example the $130 \mathrm{~nm}$ emission from atomic oxygen $[41,52]$ and /or energetic photons from excited argon or fluorine in certain LP and plasma-asher treatments. Such effects are greatly enhanced when the samples' surface-to-volume ratio is large, clearly the case for electrospun material.

Table 5 shows significant reductions in intrinsic viscosities and viscosity $M_{v}$ values for the cases of plasma-etched mats after different plasma-etching procedures. These results agree with SEM images of the treated mats, where surface degradation was observed for samples etched by LP- 
plasma in $\mathrm{O}_{2}$ and $\mathrm{Ar}+\mathrm{O}_{2}$ mixture. Decreases are also seen to be appreciable for HP- and asheretched samples, compared with the pristine sample values. This would therefore confirm that the nanofibrous polymer was indeed subject to chain scissions, resulting in reduced average chain lengths and lower values of elastic modulus $[31,52,53]$.

Table 5 Inherent and intrinsic viscosities and viscosity molecular weights for pristine and plasma-etched mats

\begin{tabular}{lcccccc} 
& $\begin{array}{c}\text { ePET } \\
\text { (pristine) }\end{array}$ & $\begin{array}{c}\mathrm{LP}-\mathrm{O}_{2} \\
\mathbf{1 5} \mathbf{~ m i n}\end{array}$ & $\begin{array}{c}\mathrm{LP}-\mathrm{O}_{2} \text {-Ar } \\
\mathbf{1 5} \mathbf{~ m i n}\end{array}$ & $\begin{array}{c}\mathrm{HP} \\
\mathbf{1 5} \mathbf{~ m i n}\end{array}$ & $\begin{array}{c}\mathrm{O}_{2}-\mathrm{CF}_{4} \text {-asher } \\
\mathbf{1} \mathbf{m i n}\end{array}$ & $\begin{array}{c}\mathrm{O}_{2} \text {-asher } \\
\mathbf{5} \mathbf{m i n}\end{array}$ \\
\hline Inherent viscosity $\left[\mathrm{dL} \cdot \mathrm{g}^{-1}\right]$ & 0.94 & 0.31 & 0.24 & 0.57 & 0.54 & 0.64 \\
Intrinsic viscosity $\left[\mathrm{dL} \cdot \mathrm{g}^{-1}\right]$ & 1.00 & 0.32 & 0.24 & 0.59 & 0.55 & 0.67 \\
Viscosity Mv $\left[\mathrm{g} \cdot \mathrm{mol}^{-1}\right.$ ] & 92450 & 19500 & 13275 & 44620 & 41255 & 53490
\end{tabular}

\subsubsection{Differential Scanning Calorimetry (DSC)}

DSC measurements were performed on all samples. Presumably, the glass transition $\left(T_{g}\right)$, cold crystallization and melting point temperatures correspond to the three peaks on the DSC thermograms (Figure 6), in order of rising $T$, all for first heating runs. Cold crystallization and melting peaks occurred at $127{ }^{\circ} \mathrm{C}$ and $252{ }^{\circ} \mathrm{C}$ in the thermograms of both pristine and etched nanofibers, but no cold crystallization peak was observed for the case of a PET pellet since it was already partially crystalline. However, the melting temperature $\left(252^{\circ} \mathrm{C}\right)$ of the pellet and ePET were the same. Hence, no major differences in thermal properties were observed between pristine and plasma-etched samples, suggesting that crystallinity did not change appreciably in the course of plasma exposure. Differences between PET mats and pellets (particularly $T_{g}$ ) are probably due to very rapid solidification during solvent evaporation while electrospinning: this presumably does not allow enough time for macromolecular ordering. 


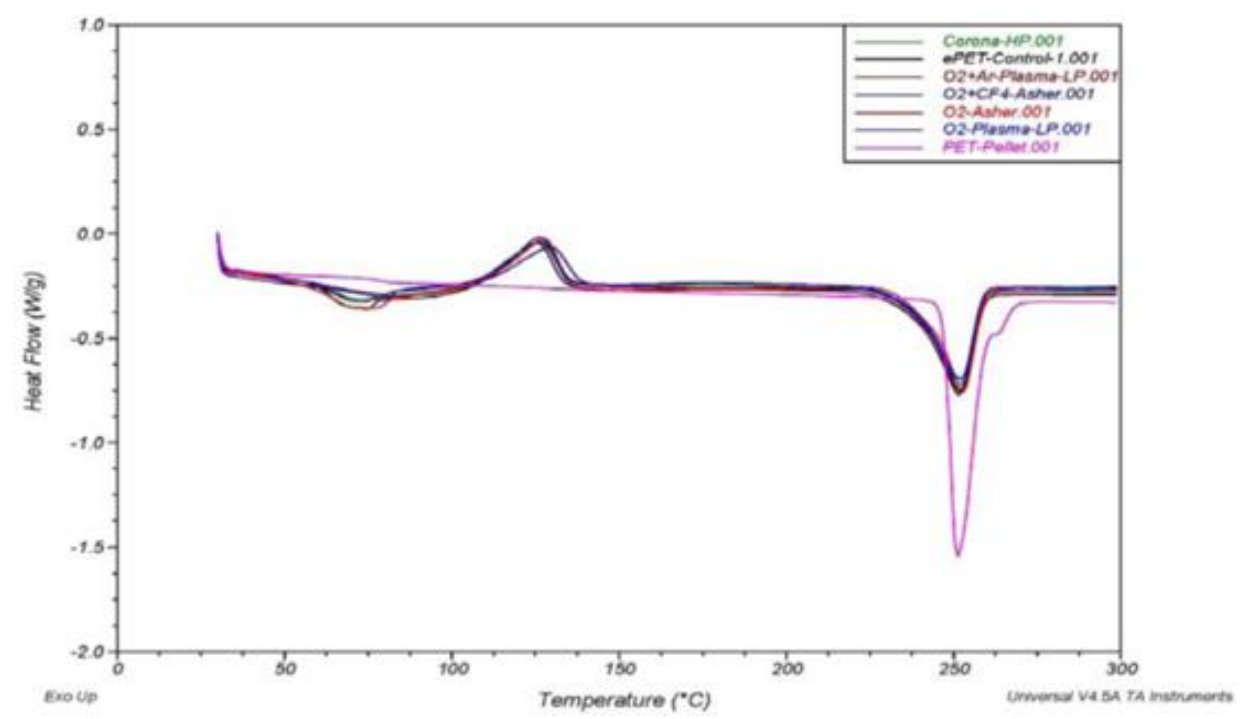

Figure 6 DSC thermograms for PET pellet, pristine and plasma-etched ePET mats, during first heating.

\subsection{Cell Adhesion, Viability and Proliferation on Pristine and Plasma-Etched Substrates}

\subsubsection{Cell adhesion and growth}

Cell adhesion and -growth was observed on both pristine and plasma-etched mats (Asher- $\mathrm{O}_{2}, 5$ min) using the AlamarBlue assay. As already pointed out above, asher-etched ePET mat $\left(\mathrm{O}_{2}, 5\right.$ min) was chosen because its mechanical properties are comparable to those of natural arteries, and because the fibers' surface morphology was unchanged (see Table 3). No significant difference in cell adhesion was observed between pristine and plasma-etched samples, which showed similar results as control PCP 24h after seeding (Figure 7).

Cell growth after 7 days was quite limited on pristine ePET, but significantly $(p<0.05)$ greater on the plasma-etched mat (Figure 7). Even more cells were found on PCP $(p<0.05)$ on day 7, but this should not be taken into account, because cells could migrate in PCP wells during the growth period and cover all areas of the well. In contrast, ePET mats were transferred to new wells before the Alamar-Blue assay, to prevent counting cells which migrated and grew on the bottoms of wells. The observed high cell count on plasma-etched mats was expected, because a similar increase had already been observed following wet-chemical or plasma treatments in $\mathrm{O}_{2}, \mathrm{CO}_{2}$ or air, for the case 
of both polymer films and electrospun mats $[15,54,55]$. It is probably due to their different surface properties (hydrophilicity, O-containing functional groups, and somewhat increased surface roughness). These may improve cell adhesion and growth via increased adsorption of proteins from the culture medium or from cell secretions, in agreement with other studies $[15,35]$.

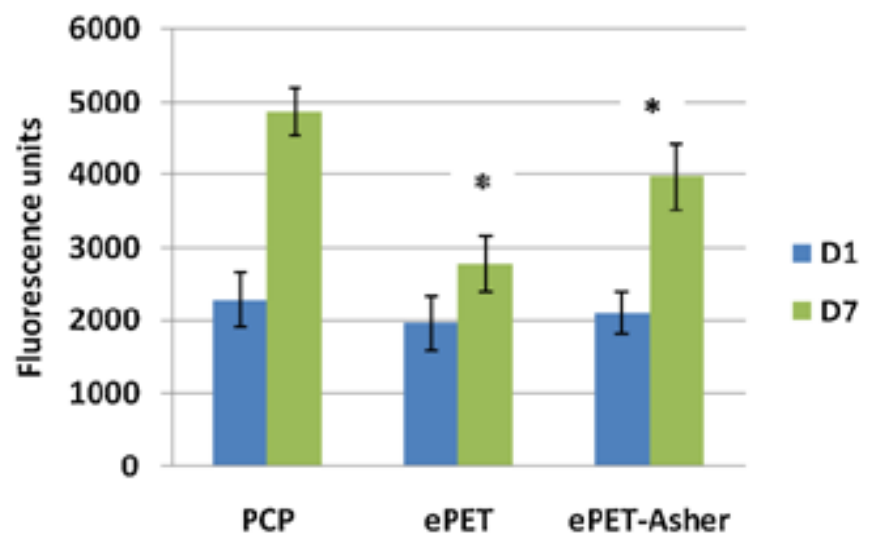

Figure 7 Adhesion $24 \mathrm{~h}$ and growth $7 \mathrm{~d}$ of VSMCs on pristine and plasma-etched substrate (PCP: tissue-culture polystyrene; ePET: electrospun mats; e-PET-Asher: plasma-etched mats) $(n=8$ for each). * Significant difference between pristine and plasma-etched ePET at day 7 $(p<0.05)$.

\subsubsection{Cell morphology}

Cell morphology was visualized on the pristine and plasma-etched mats at day 7 by SEM (Figure 8). Cells spread on both mats and oriented along or bridged between neighboring fibers. Also, they displayed a spindle-like contractile phenotype and multicellular network, and they penetrated inside the voids of both types of mats. This observation agrees with other studies that show cell migration towards the inside of nano- or micro-fibrous matrices with large pore sizes [14] [15, 56, 57]. However, SEM images merely allow one to observe cell infiltration into the very top layers of the mats; additional study by confocal microscopy is required to evaluate their deeper penetration. 

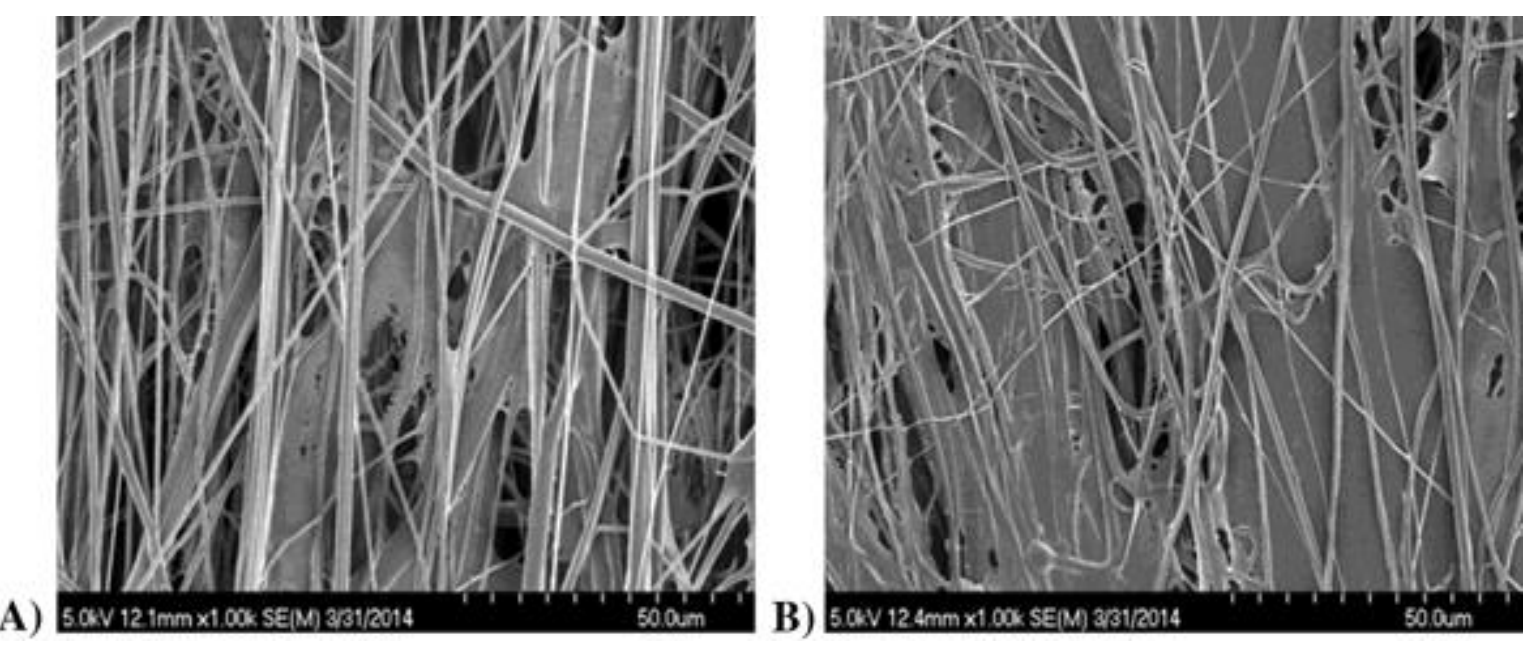

Figure 8 SEM micrographs of electrospun nanofiber mats with VSMCs after $7 \mathrm{~d}$ of growth: (A) pristine mat (ePET); (B) mat after plasma-etching (scale bar: $50 \mu \mathrm{m}$ ).

\section{General Discussion and Conclusions}

Mimicking the mechanical properties and structure of the media layer of blood vessels plays a key role in the clinical outcomes of engineered vascular graft (VG). Fabrication of a biocompatible, compliant matrix with defined structure that enables the growth of circumferentially-oriented smooth muscle cells (SMCs) remains a challenge [4]. Orientation is the key requirement for SMCs, because they are spindle-shaped and circumferentially aligned [57].

In the present study, cost-effective and easily-implemented electrospinning with a high speed rotating mandrel was used to approximate morphology and mechanical properties of the VG's SMC layer. Highly porous electrospun PET mats (ePET) were prepared with fibers well-aligned along the mandrel's circumference, advantageous for SMC growth. PET was selected because it is stable, inexpensive and cytocompatible, with tunable properties, and because several PET-based vascular implants already received FDA-approval [15, 19]. The main challenge has been excessively-high mechanical properties in the circumferential direction of the spin-aligned mats (most particularly, their high Young's modulus). Therefore, an environmentally benign process, plasma-etching, was chosen to fine-tune the mats' mechanical and surface-chemical properties.

Significant decreases in Young's modulus were observed following LP-, HP-, and asher-induced plasma etching (Figure 4). Moreover, although there is a reduction in elongation at break, the 
obtained tensile strengths are similar to those of natural arteries. These changes could be related to the reduction in fiber diameters and to nano/micro-pit surface defects observed after extended LP and HP plasma treatments. Chain scissions and concomitant decreases in molecular weight were also observed with all three etching techniques, according to intrinsic viscosity measurements (Figure 6). These can be attributed to reactive oxygen erosion, accompanied by ion bombardment and VUV-induced reactions. These are responsible for the majority of chemical alterations present, namely chain scissions accompanied by molecular weight reduction, cleavage of the polymer backbone, and possibly some cross-linking, along with surface oxidation. Prolonged etching duration could entrain deleterious effects on the ePET mats' morphology, as shown in Figure 2 for LP- and HP-plasma etched samples. Interestingly and fortunately, shortduration treatments in the plasma-asher enabled one to attain a similar decrease in Young's modulus (Figure 4) without observable damage of the fibers, which remained smooth. In addition, the average fiber diameter was reduced (Table 2) accompanied by a sharp increase in concentration of O-bearing functional groups (Table 3). Therefore, plasma etching can offer good control for tuning mechanical, morphological and surface-chemical properties of electrospun fibrous mats $[33,34,58]$. The likely presence at etched surfaces of some low molecular weight oxidized residues is not considered problematic, because they occur in very low concentration, are unlikely to be cytotoxic and, in any event, dissolve upon immersion in (aqueous) cell-culture media.

The morphology of the present aligned ePET mats (pristine and asher-etched $\left(\mathrm{O}_{2}, 5\right.$ min)) proved to be suitable for deep inward penetration of SCMs, for them to spread between fibers and along their lengths, see Figure 8. Indeed, the fabrication conditions used yielded high porosity and a relatively large average fiber diameter (Figure 2 and Table 2). This, and the ability of plasma to be sustained deep within the porous mats facilitated the infiltration of SMCs; of course, the open structure also enables ready exchange of nutrients and gas molecules. In addition to changes in mechanical characteristics, which allow the present etched ePET mats to more closely mimic natural blood vessels, plasma etching was also shown to have a large effect on wettability, observed by SCA and wicking time of a dye solution (Table 4), turning the originally hydrophobic mats into hydrophilic ones $[34,59,60]$. Increased wettability is, of course, favorable for cell adhesion and -growth: The polar chemical functionalities created by plasma-etching, for example hydroxyl, carbonyl or carboxylic groups, are known to favor cell adhesion and growth through 
increased protein adsorption [61, 62], which integrin receptors on cells' outer membrane, in turn, "recognize" and bind to. Moreover, microscopic or sub-micrometer surface roughness can also significantly affect the materials' wettability and protein adsorption [34, 58]. These combined effects showed a strong influence on cell growth after 7 days, compared with the pristine ePET mats (Figure 7). Additional modification with bioactive factors can further improve the scaffolds for $\mathrm{VG}$ applications, and this is the subject of ongoing investigations.

To conclude, in the present work LP- and HP-plasma etching, along with microwave plasma ashing, have been applied to fine-tune the mechanical and surface properties of aligned electrospun PET (ePET) mat scaffolds. The effects on morphology, mechanical properties, surface chemistry / wettability and bioactivity have been studied and reported here. Among the three etch techniques, the plasma asher (with pure oxygen) seems to be most advantageous in terms of rapidity, minimal apparent damage to fiber surfaces, along with efficacy in changing mechanical properties. Thus, the combination of electrospinning and appropriate plasma-etching can provide an adequate (3D) scaffold for the media layer of small-diameter vascular prostheses; more precisely, it enables one to achieve finely-controlled structural, mechanical and surface properties that are required for VG applications.

Acknowledgments

This research is being supported by grants from the Natural Sciences and Engineering Research Council of Canada (NSERC) and the Canadian Institutes of Health Research (CIHR) (CPG 87497). One of us (H.S.) gratefully acknowledges the Fonds de recherche du Québec-Nature et technologies (FQRNT) for the award of its Merit Scholarship. The authors thank C. Cerclé, N. MacDonald, S. Poulin, Dr. J. Lefebvre, Y. Leblanc (all at École Polytechnique de Montréal), and Dr. M. Maire (CR-CHUM) for skilled technical support and help during some of the experiments, and École's Microfabrication Laboratory (LMF) for providing access to the plasma-ash apparatus. 
[1] D.G. Seifu, A. Purnama, K. Mequanint, D. Mantovani, Small-diameter vascular tissue engineering, Nature Reviews Cardiology 10(7) (2013) 410-421.

[2] N. L'Heureux, N. Dusserre, A. Marini, S. Garrido, L. de la Fuente, T. McAllister, Technology Insight: the evolution of tissue-engineered vascular grafts-from research to clinical practice, Nature Clinical Practice Cardiovascular Medicine 4(7) (2007) 389-395.

[3] B.C. Isenberg, J.Y. Wong, Building structure into engineered tissues, Materials Today 9(12) (2006) 54-60.

[4] A. Ratcliffe, Tissue engineering of vascular grafts, Matrix Biology 19(4) (2000) 353-357.

[5] M.K. O'Connell, S. Murthy, S. Phan, C. Xu, J. Buchanan, R. Spilker, R.L. Dalman, C.K. Zarins, W. Denk, C.A. Taylor, The three-dimensional micro- and nanostructure of the aortic medial lamellar unit measured using 3D confocal and electron microscopy imaging, Matrix Biology 27(3) (2008) 171-181.

[6] A. Hasan, A. Memic, N. Annabi, M. Hossain, A. Paul, M.R. Dokmeci, F. Dehghani, A. Khademhosseini, Electrospun scaffolds for tissue engineering of vascular grafts, Acta Biomater. 10(1) (2014) 11-25.

[7] N. L'Heureux, N. Dusserre, A. Marini, S. Garrido, L. de la Fuente, T. McAllister, Technology Insight: the evolution of tissue-engineered vascular grafts - from research to clinical practice, Nat. Clin. Pract. Cardiovasc. Med. 4(7) (2007) 389-395.

[8] T.J. Sill, H.A. von Recum, Electro spinning: Applications in drug delivery and tissue engineering, Biomaterials 29(13) (2008) 1989-2006.

[9] M.J. McClure, S.A. Sell, C.E. Ayres, D.G. Simpson, G.L. Bowlin, Electrospinning-aligned and random polydioxanone-polycaprolactone-silk fibroin-blended scaffolds: geometry for a vascular matrix, Biomed. Mater. 4(5) (2009) 13.

[10] H.J. Wu, J.T. Fan, C.C. Chu, J. Wu, Electrospinning of small diameter 3-D nanofibrous tubular scaffolds with controllable nanofiber orientations for vascular grafts, J. Mater. Sci.-Mater. Med. 21(12) (2010) 3207-3215.

[11] Y.B. Zhu, Y. Cao, J. Pan, Y.X. Liu, Macro-Alignment of Electrospun Fibers For Vascular Tissue Engineering, J. Biomed. Mater. Res. Part B 92B(2) (2010) 508-516.

[12] C.Y. Xu, R. Inai, M. Kotaki, S. Ramakrishna, Aligned biodegradable nanotibrous structure: a potential scaffold for blood vessel engineering, Biomaterials 25(5) (2004) 877-886.

[13] V. Thomas, M.V. Jose, S. Chowdhury, J.F. Sullivan, D.R. Dean, Y.K. Vohra, Mechanomorphological studies of aligned nanofibrous scaffolds of polycaprolactone fabricated by electrospinning, J. Biomater. Sci.-Polym. Ed. 17(9) (2006) 969-984.

[14] L. Nivison-Smith, A.S. Weiss, Alignment of human vascular smooth muscle cells on parallel electrospun synthetic elastin fibers, Journal of Biomedical Materials Research Part A 100A(1) (2012) 155-161.

[15] A. Hadjizadeh, A. Ajji, M. Jolicoeur, B. Liberelle, G. De Crescenzo, Effects of electrospun nanostructure versus microstructure on human aortic endothelial cell behavior, J. Biomed. Nanotechnol. 9(7) (2013) 1195-1209. 
[16] M.J. Moreno, A. Ajji, D. Mohebbi-Kalhori, M. Rukhlova, A. Hadjizadeh, M.N. Bureau, Development of a compliant and cytocompatible micro-fibrous polyethylene terephthalate vascular scaffold, J. Biomed. Mater. Res. Part B 97B(2) (2011) 201-214.

[17] W. He, T. Yong, W.E. Teo, Z.W. Ma, S. Ramakrishna, Fabrication and endothelialization of collagen-blended biodegradable polymer nanofibers: Potential vascular graft for blood vessel tissue engineering, Tissue Eng. 11(9-10) (2005) 1574-1588.

[18] M.C. Burrows, V.M. Zamarion, F.B. Filippin-Monteiro, D.C. Schuck, H.E. Toma, A. Campa, C.R.S. Garcia, L.H. Catalani, Hybrid Scaffolds Built From PET and Collagen as a Model For Vascular Graft Architecture, Macromol. Biosci. 12(12) (2012) 1660-1670.

[19] H. Savoji, A. Hadjizadeh, M. Maire, A. Ajji, M.R. Wertheimer, S. Lerouge, Electrospun Nanofiber Scaffolds and Plasma Polymerization: A Promising Combination Towards Complete, Stable Endothelial Lining for Vascular Grafts, Macromolecular Bioscience 14(8) (2014) 10841095.

[20] A. Hadjizadeh, A. Ajji, M.N. Bureau, Preparation and characterization of $\mathrm{NaOH}$ treated micro-fibrous polyethylene terephthalate nonwovens for biomedical application, Journal of the Mechanical Behavior of Biomedical Materials 3(8) (2010) 574-583.

[21] R. Ng, X.D. Zhang, N. Liu, S.T. Yang, Modifications of nonwoven polyethylene terephthalate fibrous matrices via $\mathrm{NaOH}$ hydrolysis: Effects on pore size, fiber diameter, cell seeding and proliferation, Process Biochem. 44(9) (2009) 992-998.

[22] J.H. Lee, S.H. Park, K.W. Oh, C.H. Lee, S.H. Kim, Effect of pretreatment conditions on the hydrolysis and water absorption behavior of poly(ethylene terephthalate) fibrous assembly, Polym. Int. 61(4) (2012) 657-663.

[23] W. Kosorn, B. Thavornyutikarn, W. Janvikul, Effects of Surface Treatments of Polycaprolactone Scaffolds on Their Properties, in: N. Sombatsompop, D. Bhattacharyya, K.H.Y. Cheung (Eds.), Multi-Functional Materials and Structures Trans Tech Publications Ltd, StafaZurich, 2013, pp. 178-181.

[24] S.G. Jordan, G.R. Gray, A. Malhotra, Chemical-mechanical etch (CME) method for patterned etching of a substrate surface, Google Patents, 2002.

[25] M. Rahman, G.C. East, Titanium Dioxide Particle-induced Alkaline Degradation of Poly(ethylene Terephthalate): Application to Medical Textiles, Text. Res. J. 79(8) (2009) 728-736.

[26] E.S. Kim, C.H. Lee, S.H. Kim, Effects of Pretreatment Reagents on the Hydrolysis and Physical Properties of PET Fabrics, J. Appl. Polym. Sci. 112(5) (2009) 3071-3078.

[27] R. Morent, N. De Geyter, J. Verschuren, K. De Clerck, P. Kiekens, C. Leys, Non-thermal plasma treatment of textiles, Surf. Coat. Technol. 202(14) (2008) 3427-3449.

[28] D. Hegemann, H. Brunner, C. Oehr, Plasma treatment of polymers for surface and adhesion improvement, Nuclear Instruments and Methods in Physics Research Section B: Beam Interactions with Materials and Atoms 208 (2003) 281-286.

[29] X. Chen, L. Yao, J. Xue, D. Zhao, Y. Lan, X. Qian, C.X. Wang, Y. Qiu, Plasma penetration depth and mechanical properties of atmospheric plasma-treated 3D aramid woven composites, Appl. Surf. Sci. 255(5) (2008) 2864-2868. 
[30] M.O.H. Cioffi, H.J.C. Voorwald, L.R.O. Hein, L. Ambrosio, Effect of cold plasma treatment on mechanical properties of PET/PMMA composites, Compos. Pt. A-Appl. Sci. Manuf. 36(5) (2005) 615-623.

[31] C. Riccardi, R. Barni, E. Selli, G. Mazzone, M.R. Massafra, B. Marcandalli, G. Poletti, Surface modification of poly(ethylene terephthalate) fibers induced by radio frequency air plasma treatment, Appl. Surf. Sci. 211(1-4) (2003) 386-397.

[32] M. Keller, A. Ritter, P. Reimann, V. Thommen, A. Fischer, D. Hegemann, Comparative study of plasma-induced and wet-chemical cleaning of synthetic fibers, Surf. Coat. Technol. 200(1-4) (2005) 1045-1050.

[33] P. Verdonck, P.B. Caliope, E.D. Hernandez, A.N.R. da Silva, Plasma etching of electrospun polymeric nanofibres, Thin Solid Films 515(2) (2006) 831-834.

[34] C. Zanden, M. Voinova, J. Gold, D. Morsdorf, I. Bernhardt, J.H. Liu, Surface characterisation of oxygen plasma treated electrospun polyurethane fibres and their interaction with red blood cells, Eur. Polym. J. 48(3) (2012) 472-482.

[35] H.J. Jeon, H. Lee, G.H. Kim, Nano-Sized Surface Patterns on Electrospun Microfibers Fabricated Using a Modified Plasma Process for Enhancing Initial Cellular Activities, Plasma Process. Polym. 11(2) (2014) 142-148.

[36] A. Hadjizadeh, A. Ajji, M.N. Bureau, Nano/micro electro-spun polyethylene terephthalate fibrous mat preparation and characterization, Journal of the Mechanical Behavior of Biomedical Materials 4(3) (2011) 340-351.

[37] F. Truica-Marasescu, M.R. Wertheimer, Nitrogen-rich plasma-polymer films for biomedical applications, Plasma Process. Polym. 5(1) (2008) 44-57.

[38] S. Guimond, I. Radu, G. Czeremuszkin, D.J. Carlsson, M.R. Wertheimer, Biaxially oriented polypropylene (BOPP) surface modification by nitrogen atmospheric pressure glow discharge (APGD) and by air corona, Plasmas Polym. 7(1) (2002) 71-88.

[39] S. Guimond, M.R. Wertheimer, Surface degradation and hydrophobic recovery of polyolefins treated by air corona and nitrogen atmospheric pressure glow discharge, J. Appl. Polym. Sci. 94(3) (2004) 1291-1303.

[40] M. Moisan, C. Barbeau, R. Claude, C.M. Ferreira, J. Margot, J. Paraszczak, A.B. Sa, G. Sauve, M.R. Wertheimer, RADIO-FREQUENCY OR MICROWAVE PLASMA REACTORS FACTORS DETERMINING THE OPTIMUM FREQUENCY OF OPERATION, J. Vac. Sci. Technol. B 9(1) (1991) 8-25.

[41] B. Lamontagne, O.M. Küttel, M.R. Wertheimer, Etching of polymers in microwave/radiofrequency O2-CF4 plasma, Canadian Journal of Physics 69(3-4) (1991) 202-206.

[42] C.E. Ayres, B.S. Jha, H. Meredith, J.R. Bowman, G.L. Bowlin, S.C. Henderson, D.G. Simpson, Measuring fiber alignment in electrospun scaffolds: a user's guide to the 2D fast Fourier transform approach, Journal of Biomaterials Science, Polymer Edition 19(5) (2008) 603-621.

[43] C. Ayres, G.L. Bowlin, S.C. Henderson, L. Taylor, J. Shultz, J. Alexander, T.A. Telemeco, D.G. Simpson, Modulation of anisotropy in electrospun tissue-engineering scaffolds: Analysis of fiber alignment by the fast Fourier transform, Biomaterials 27(32) (2006) 5524-5534. 
[44] S. De Valence, J.-C. Tille, J.-P. Giliberto, W. Mrowczynski, R. Gurny, B. Walpoth, M. Moeller, Advantages of bilayered vascular grafts for surgical applicability and tissue regeneration, Acta Biomater. 8(11) (2012) 3914-3920.

[45] H. Savoji, D. Rana, T. Matsuura, S. Tabe, C. Feng, Development of plasma and/or chemically induced graft co-polymerized electrospun poly (vinylidene fluoride) membranes for solute separation, Separation and Purification Technology 108 (2013) 196-204.

[46] B.H. Bimestre, C. Saron, Chain extension of poly (ethylene terephthalate) by reactive extrusion with secondary stabilizer, Materials Research 15 (2012) 467-472.

[47] N.B. Sanches, M.L. Dias, E.B.A.V. Pacheco, Comparative techniques for molecular weight evaluation of poly (ethylene terephthalate) (PET), Polymer Testing 24(6) (2005) 688-693.

[48] S.A. Sell, M.J. McClure, C.P. Barnes, D.C. Knapp, B.H. Walpoth, D.G. Simpson, G.L. Bowlin, Electrospun polydioxanone-elastin blends: potential for bioresorbable vascular grafts, Biomed. Mater. 1(2) (2006) 72.

[49] N. De Geyter, R. Morent, C. Leys, Penetration of a dielectric barrier discharge plasma into textile structures at medium pressure, Plasma Sources Science and Technology 15(1) (2006) 78.

[50] C.X. Wang, Y. Liu, H.L. Xu, Y. Ren, Y.P. Qiu, Influence of atmospheric pressure plasma treatment time on penetration depth of surface modification into fabric, Appl. Surf. Sci. 254(8) (2008) 2499-2505.

[51] J. Johansson, T. Masuoka, Penetration of pores in membranes by plasma polymer forming species, Macromolecular Rapid Communications 20(1) (1999) 12-15.

[52] A. Guex, F. Kocher, G. Fortunato, E. Körner, D. Hegemann, T. Carrel, H. Tevaearai, M. Giraud, Fine-tuning of substrate architecture and surface chemistry promotes muscle tissue development, Acta Biomater. 8(4) (2012) 1481-1489.

[53] Y. Qiu, Y. Hwang, C. Zhang, B. Bures, M. McCord, Atmospheric pressure helium+ oxygen plasma treatment of ultrahigh modulus polyethylene fibers, Journal of adhesion science and technology 16(4) (2002) 449-457.

[54] A. Dekker, K. Reitsma, T. Beugeling, A. Bantjes, J. Feijen, W. Van Aken, Adhesion of endothelial cells and adsorption of serum proteins on gas plasma-treated polytetrafluoroethylene, Biomaterials 12(2) (1991) 130-138.

[55] T. Jacobs, R. Morent, N. De Geyter, P. Dubruel, C. Leys, Plasma surface modification of biomedical polymers: influence on cell-material interaction, Plasma Chemistry and Plasma Processing 32(5) (2012) 1039-1073.

[56] C.Y. Xu, R. Inai, M. Kotaki, S. Ramakrishna, Aligned biodegradable nanofibrous structure: a potential scaffold for blood vessel engineering, Biomaterials 25(5) (2004) 877-886.

[57] B.M. Baker, A.O. Gee, R.B. Metter, A.S. Nathan, R.A. Marklein, J.A. Burdick, R.L. Mauck, The potential to improve cell infiltration in composite fiber-aligned electrospun scaffolds by the selective removal of sacrificial fibers, Biomaterials 29(15) (2008) 2348-2358.

[58] Q. Cheng, B.L.-P. Lee, K. Komvopoulos, Z. Yan, S. Li, Plasma surface chemical treatment of electrospun poly (L-lactide) microfibrous scaffolds for enhanced cell adhesion, growth, and infiltration, Tissue Engineering Part A 19(9-10) (2013) 1188-1198. 
[59] B. De Schoenmaker, L. Van der Schueren, S. De Vrieze, P. Westbroek, K. De Clerck, Wicking properties of various polyamide nanofibrous structures with an optimized method, J. Appl. Polym. Sci. 120(1) (2011) 305-310.

[60] K. Wong, X. Tao, C. Yuen, K. Yeung, Wicking properties of linen treated with low temperature plasma, Text. Res. J. 71(1) (2001) 49-56.

[61] D. Yan, J. Jones, X. Yuan, X. Xu, J. Sheng, J.M. Lee, G. Ma, Q. Yu, Plasma treatment of electrospun PCL random nanofiber meshes (NFMs) for biological property improvement, Journal of Biomedical Materials Research Part A 101(4) (2013) 963-972.

[62] M. Yamaguchi, T. Shinbo, T. Kanamori, P.-c. Wang, M. Niwa, H. Kawakami, S. Nagaoka, K. Hirakawa, M. Kamiya, Surface modification of poly (L-lactic acid) affects initial cell attachment, cell morphology, and cell growth, Journal of Artificial Organs 7(4) (2004) 187-193. 